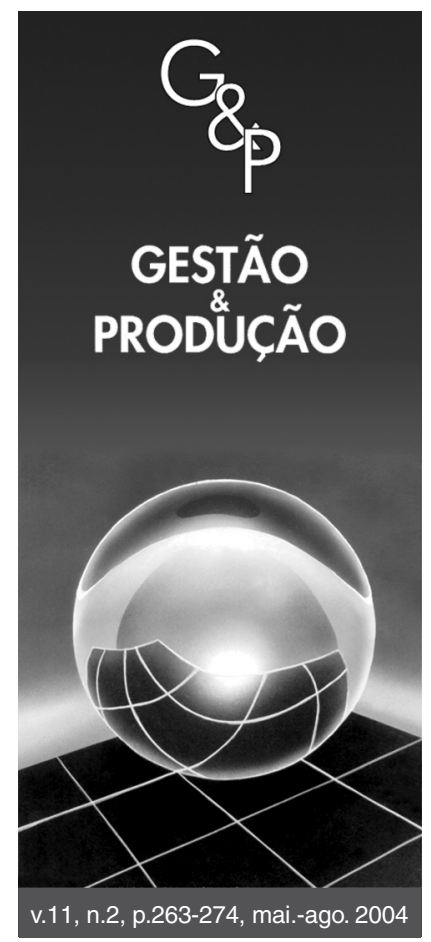

\title{
EMPOWERMENT: ESTUDO DE CASOS EM EMPRESAS MANUFATUREIRAS
}

\author{
Claudia Heloisa Ribeiro Rodrigues \\ Universidade de São Paulo, Escola de Engenharia de São Carlos, \\ Avenida Trabalhador São-carlense, 400, São Carlos, SP, CEP 13566-590, \\ e-mail: cacau_rodrigues@ @otmail.com \\ Fernando César Almada Santos \\ Universidade de São Paulo, Escola de Engenharia de São Carlos, \\ Departamento de Engenharia de Produção, \\ Avenida Trabalhador São-carlense, 400, São Carlos, SP, CEP 13566-590, \\ e-mail: almada@prod.eesc.sc.usp.br
}

\section{Resumo}

Recebido em 21/7/2003 Aceito em 31/5/2004

O objetivo deste artigo é analisar o desenvolvimento do empowerment em duas empresas manufatureiras. Empowerment é uma abordagem de projeto de trabalho que objetiva a delegação de poder de decisão, autonomia e participação dos funcionários na administração das empresas. Analisa-se o desenvolvimento do empowerment por meio dos estágios evolutivos das áreas de gestão, das configurações organizacionais, das estratégias competitivas, da gestão de recursos humanos e da qualidade. Apresenta-se um estudo de casos em duas empresas manufatureiras do interior de São Paulo, a fim de se analisar o grau de participação dos funcionários de acordo com o estágio evolutivo de suas áreas de gestão. Nas conclusões, discutem-se os fatores favoráveis, as particularidades e limitações do empowerment com base nos estudos de casos.

Palavras-chave: empowerment, estágios evolutivos das áreas de gestão, gestão de recursos humanos, gestão da qualidade, estratégia empresarial.

\section{Introdução}

O empowerment é uma abordagem de projeto de trabalho que objetiva a delegação de poder de decisão, autonomia e participação dos funcionários na administração das empresas. Busca-se o comprometimento dos empregados em contribuir para as decisões estratégicas, com o objetivo de melhorar o desempenho da organização. É uma alternativa para o paradigma tradicional de gestão. O novo paradigma está focado na desburocratização, na descentralização, na flexibilização e na inovação (Herrenkohl, Judson e Heffner, 1999; Cunningham e Hyman, 1999; Wilkinson, 1997; Pfeiffer e Dunlop, 1990).

O desenvolvimento do empowerment, entretanto, necessita de um contexto organizacional que viabilize a descentralização da decisão, o compartilhamento da informação e a autonomia (Wilkinson, 1998).

Vale destacar que não existe um termo único em português para o significado de empowerment. Na língua inglesa, o termo significa "the process of giving somebody the power of act" (Oxford Advanced Learner's Dictionary, 1995). Desta forma, neste artigo, será mantido o termo da língua inglesa.

Este artigo é uma continuidade da revisão bibliográfica sobre o ciclo de implementação, dimensões e tipologias do empowerment (Rodrigues e Santos, 2001). Inicialmente, realiza-se uma breve revisão bibliográfica sobre o desenvolvimento do empowerment, por meio dos estágios evolutivos das áreas de gestão. Em seguida, apresenta-se um estudo de casos em duas empresas manufatureiras do Estado de São Paulo, a fim de se analisar o desenvolvimento do empowerment nestas empresas nos últimos dez anos, ou seja, no período de 1993 a 2002.

\section{Tipos de empowerment}

Ford e Fottler (1996) usam dois parâmetros para propor diferentes tipos de empowerment: a autoridade para tomada de decisão sobre o contexto do trabalho e a autoridade para tomada de decisão sobre o conteúdo do trabalho (Figura 1).

No Ponto A, não há literalmente nenhum poder de toma- 
da de decisão associada ao trabalho, nem em termos de conteúdo do trabalho nem de contexto do trabalho. Este ponto representa o trabalho altamente repetitivo da linha de montagem tradicional (Ford e Fottler, 1996).

No Ponto B, o estabelecimento de atividades representa a essência dos programas de empowerment usados atualmente. Aqui, ao trabalhador é dada uma grande responsabilidade para decidir sobre o conteúdo do trabalho, e pouca para o contexto (Ford e Fottler, 1996).

No Ponto C, o empowerment participativo representa uma área mais típica de grupos de trabalho autônomos, os quais são usualmente envolvidos na identificação de problemas, busca de alternativas e recomendação da melhor alternativa para o conteúdo do trabalho (Ford e Fottler, 1996).

No Ponto D, a definição de missão representa uma situação incomum e raramente discutida na literatura de $\mathrm{em}$ powerment. Um exemplo poderia ser uma equipe em uma operação de manutenção sindicalizada, à qual é dada a tarefa de decidir se uma atividade seria melhor realizada por um terceiro ou pelos atuais empregados (Ford e Fottler, 1996).
No Ponto E, o auto-gerenciamento representa uma área em que aos empregados é dada total autoridade, para a tomada de decisão sobre conteúdo do trabalho e contexto do trabalho. Para fazer isto, há a necessidade de grande confiança na capacidade dos funcionários usarem o recém-conhecido empowerment no sentido de contribuir para a eficácia organizacional. Isto requer extensivo envolvimento dos empregados no desenvolvimento da missão e das metas da organização, e a confiança de que o funcionário está pronto, desejoso e capaz de tomar decisões em seu trabalho, que reflitam contribuições sábias, inteligentes e apropriadas aos objetivos da organização (Ford e Fottler, 1996).

\section{Empowerment e estágios evolutivos das áreas de gestão}

Busca-se, a seguir, associar o empowerment aos estágios evolutivos das áreas de gestão como propostos por Santos (2001).

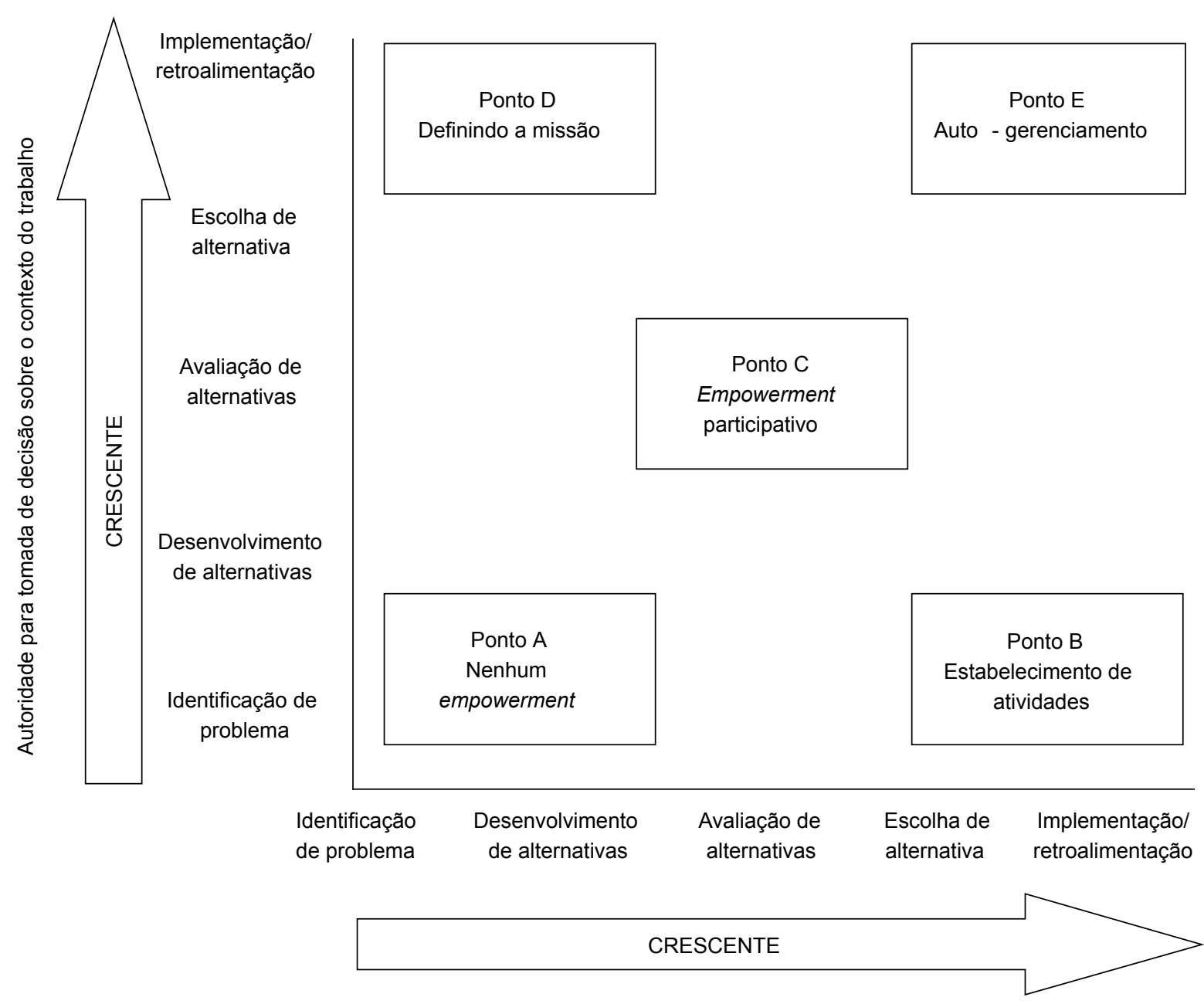

Autoridade para tomada de decisão sobre conteúdo do trabalho

Figura 1. Tipos de empowerment do funcionário (Ford e Fottler, 1996, p. 21). 


\subsection{Empowerment no estágio de iniciação funcional}

A iniciação das áreas funcionais ocorre em organizações com estrutura simples (Mintzberg, 1995). Neste caso, ocorre a centralização da estratégia na figura do dono da empresa, isto é, o dono possui o poder de decisão do que deverá ou não ser feito.

Durante a iniciação funcional da qualidade, os esforços se voltam para a inspeção da qualidade. A inspeção da qualidade, nesta fase, ainda é realizada de maneira informal pelo dono da empresa, que verifica se o produto foi ou não "bem feito" (Garvin, 1992.).

Neste estágio, pode-se dizer que ocorre um empowerment informal dos funcionários, em razão da pouca e simples estrutura da organização e da baixa qualificação do trabalhador. Pode-se dizer que este possui a liberdade de dar "palpites" informais para executar seu trabalho.

\subsection{Empowerment no estágio de especialização funcional}

Empresas com esta configuração organizacional são denominadas burocracias mecanizadas (Mintzberg, 1995). Neste estágio, o controle é exercido de forma intensa para coordenação do trabalho, de modo a agilizar o processo e minimizar as interrupções. As empresas de produção em massa são as mais conhecidas neste estágio.

Nesse estágio, a gestão de recursos humanos deve se especializar em encontrar as pessoas certas para sustentar o crescimento e treiná-las para realizar tarefas emergentes na organização. A rigidez da estrutura organizacional, de suas unidades organizacionais e de seus cargos, torna identicamente rígidas as várias atividades de recursos humanos, tais como o gerenciamento de carreiras, a análise e descrição de cargos, os programas de treinamento e os sistemas de remuneração.

Geralmente, as empresas que se encontram no estágio de especialização funcional optam, predominantemente, pela estratégia de redução de custos "através de controles mais rígidos, minimização de custo administrativo e busca de economia de escala" (Schuler e Jackson, 1995).

No estágio de especialização funcional da área de gestão da qualidade, os esforços voltam-se para a inspeção da qualidade e o controle estatístico do processo produtivo. A qualidade do produto era definida como sinônimo de perfeição técnica. Esta conceituação de qualidade estava baseada no produto e na produção (Garvin, 1992).

No estágio de especialização funcional, a excessiva focalização no conteúdo do trabalho leva à criação de estruturas funcionais rígidas, que favorecem a centralização dos processos de tomada de decisão. A este estágio está associado nenhum empowerment, como mostrado no Ponto A da Figura 1. Há a possibilidade de ocorrer o estabelecimento de atividades, apresentado no Ponto B da Figura 1, porém os funcionários não participam da tomada de decisões estratégicas da empresa, podendo, unicamente, realizar mudanças em seus procedimentos de trabalho.

\subsection{Empowerment no estágio de integração interna}

No estágio de integração interna, as empresas criam divisões para atuar em mercados diversificados, e os gerentes divisionais necessitam de poder para administrar sua divisão, que, geralmente, tem a estrutura da burocracia mecanizada (Mintzberg, 1995).

A especialização das unidades organizacionais, a padronização dos processos de trabalho e as atividades de controle passam a conviver com atividades de planejamento, o que permite a redefinição constante de objetivos estratégicos. A preocupação estratégica passa, além do custo de produção, para a qualidade e para a diferenciação, para atender aos mercados correntes.

A crescente diferenciação de produtos e consequiente criação de divisões tornam necessário gerenciar os recursos humanos distintamente em cada divisão (Santos, 1998). Pelo fato das divisões se configurarem como burocracias mecanizadas, a área de recursos humanos não tem participação efetiva no planejamento estratégico, se restringindo apenas à sua integração em âmbito divisional (Meshoulam e Baird, 1987).

Neste momento, a gestão da qualidade passa a se preocupar com a garantia da qualidade e a prevenção de problemas, incorporando conceitos gerenciais como: quantificação dos custos de qualidade, controle total da qualidade, engenharia da confiabilidade e "zero defeito" (Garvin, 1992).

É importante frisar que a centralização de poder decisório, por parte da gerência divisional, não permite que representantes das áreas funcionais contemplem o contexto do trabalho de forma a visualizar as necessidades do ambiente competitivo e levar colaborações efetivas, para a gestão da estratégia empresarial (Mintzberg, 1995). Aperfeiçoam-se os processos decisórios, porém sua evolução limita-se ao contexto do trabalho, com o objetivo de apoiar internamente a estratégia empresarial. A este estágio de integração interna está associado, inicialmente, o estabelecimento de atividades, apresentado no Ponto B da Figura 1. À medida que as divisões aprofundam o relacionamento com seu ambiente competitivo, intensificam e descentralizam seus processos decisórios, caminha-se para o empowerment participativo (Ponto C da Figura 1).

\subsection{Empowerment no estágio de integração externa}

No estágio de integração externa, as empresas operam em um ambiente competitivo no qual a característica principal é a complexidade, isto é, para competir, as empresas necessitam estar sempre alterando suas linhas de produtos. Como as empresas organizam-se em equipes ad hoc, esta configuração denominada-se adhocracia (Mintzberg, 1995).

Há uma necessidade de constante alinhamento da gestão de recursos humanos com a direção estratégica dos negócios, o que exige uma postura pró-ativa desta área funcional, obtida por meio de um alto nível de envolvimento na organi- 


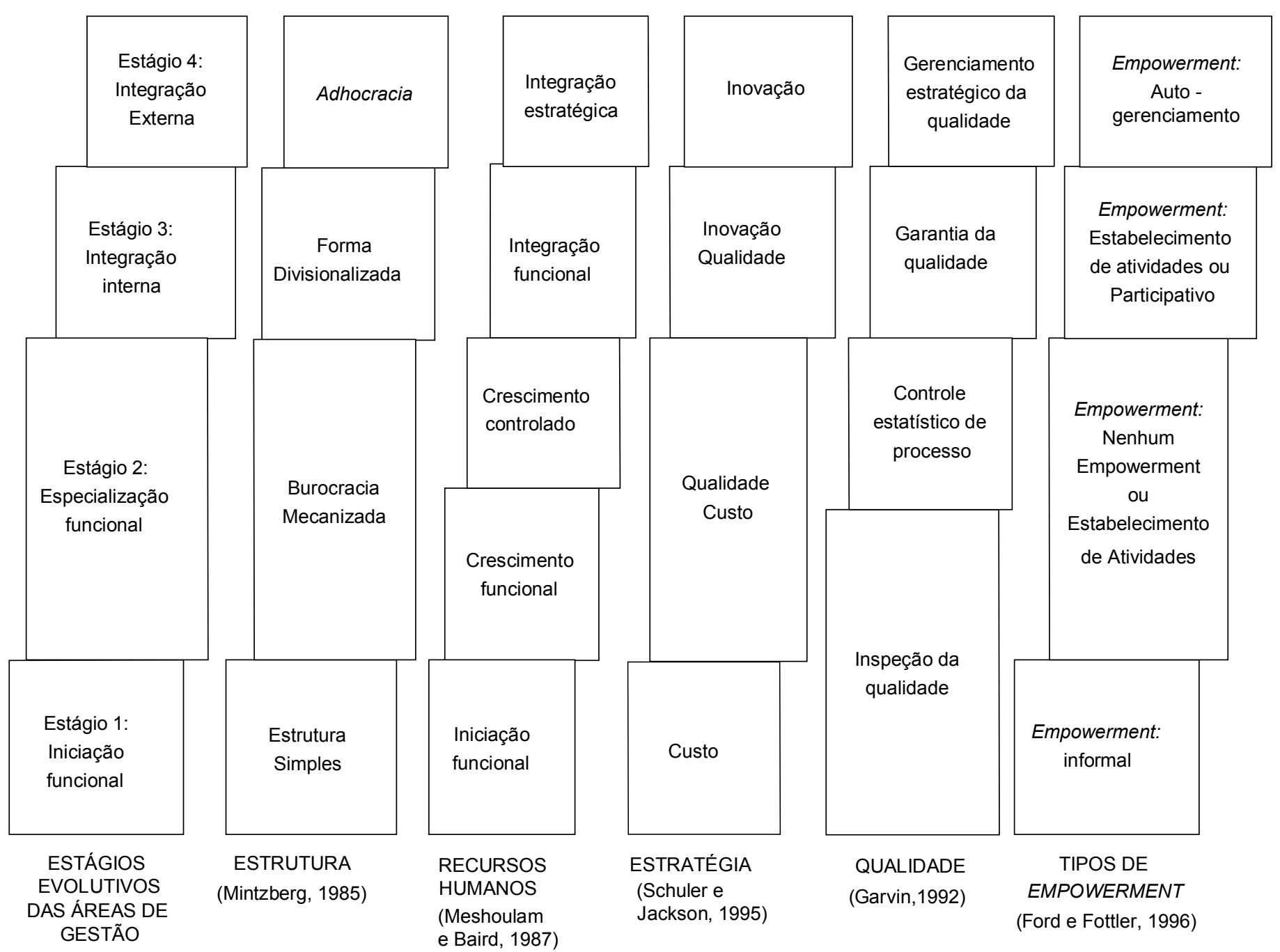

Figura 2. Relacionamento do empowerment com estrutura, gestão de recursos humanos, estratégia, gestão da qualidade e estágios evolutivos das áreas de gestão.

zação e habilidade de tratar as macro-questões (Meshoulam e Baird, 1987).

A gestão da qualidade passa a colaborar com a formulação da estratégia empresarial e com todas as etapas do processo produtivo, desde marketing a pesquisa e desenvolvimento.

A gestão estratégica da qualidade privilegia dimensões da qualidade, que aumentam a competitividade do produto em nichos da qualidade. A qualidade do produto passa a depender da qualidade do sistema produtivo, e a satisfação do cliente depende do que a concorrência oferece (Garvin, 1992).

No estágio de integração externa, as áreas funcionais passam a participar efetivamente da formulação de estratégias de negócios a partir do diagnóstico do ambiente competitivo e do contexto do trabalho. À estrutura departamental sobrepõem-se equipes interfuncionais para levar adiante programas de inovação. A este estágio evolutivo das áreas funcionais, tem-se associado o empowerment do tipo autogerenciamento (Ponto E da Figura 1).
A Figura 2 relaciona os estágios evolutivos das áreas de gestão com as configurações organizacionais, a gestão de recursos humanos, a estratégia empresarial, a gestão da qualidade e o desenvolvimento do empowerment.

\section{Estudo de casos}

Neste item é analisado o desenvolvimento do empowerment em duas empresas manufatureiras com base no arcabouço teórico desenvolvido anteriormente.

\subsection{Metodologia adotada na pesquisa}

Nesta pesquisa, pretende-se analisar o processo produtivo, o histórico da empresa e sua atuação no mercado nos últimos dez anos. A escolha dessas empresas deve-se à potencialidade de se realizar uma análise comparativa dos processos de desenvolvimento e dos tipos de empowerment com o estágio evolutivo das áreas de gestão da empresa, verificar as estratégias competitivas, os programas de qualidade, bem 
como a gestão de recursos humanos que viabilizaram esta abordagem de projeto de trabalho (Rodrigues, 2002).

Investigam-se as seguintes questões teóricas e práticas sobre empowerment:

- desenvolvimento do empowerment na empresa;

- relacionamento entre o desenvolvimento do empowerment e o estágio evolutivo das áreas de gestão;

- relacionamento entre empowerment e a estratégia competitiva adotada pela organização e o grau de participação do funcionário na elaboração de estratégias da manufatura;

- programas de qualidade utilizados na empresa;

- políticas de recursos humanos compatíveis com o empowerment, tais como clareza de metas para os funcionários, autonomia dos funcionários para definir as metas na manufatura, competências e habilidades individuais e de equipe, adquiridas durante o empowerment;

- programas de treinamento e desenvolvimento associados ao empowerment; e

- participação dos funcionários no estabelecimento de índices de desempenho.

Foram escolhidas duas empresas situadas no interior do Estado de São Paulo, que possuíam as seguintes características:

- empresas manufatureiras do setor metal-mecânico;

- empresas líderes de mercado que estão enfrentando alto nível de concorrência; e

- empresas que operam com processos produtivos diferenciados: a primeira apresenta processo de produção em massa e a segunda, por lotes ou encomenda.

A pesquisa realizada tem um caráter exploratório e foi realizada por meio de entrevistas estruturadas, aplicadas em visitas técnicas. As entrevistas foram aplicadas aos seguintes gerentes: geral da organização, de recursos humanos, de desenvolvimento de produto, de qualidade e de produção, de cada empresa estudada. Na Empresa A, foram entrevistados somente o gerente de produção e o de recursos humanos, pelo fato de a empresa não possuir, nesta unidade, os gerentes geral, de qualidade e de desenvolvimento de produto. A pesquisa foi realizada durante o segundo semestre de 2002. Assim sendo, todas as informações aqui colocadas referemse a este período de tempo.

Relacionam-se as questões e as práticas utilizadas nas empresas. Por fim, realiza-se uma análise comparativa entre a bibliografia pesquisada e a realidade nas empresas.

A Empresa A caracteriza-se como uma das plantas in- dustriais da Divisão Brasil de uma empresa multinacional sueca. A segunda empresa estudada, Empresa B, constitui a Divisão Brasil de uma empresa multinacional norte-americana (Tabela 1).

A Empresa A faz parte de uma grande corporação que atua em diversos mercados: farmacêutico, automotivo, telecomunicação, compressores e ferramentas, madeira, indústria de rolamentos, indústria elétrica e de eletrodomésticos. As empresas do grupo sueco movimentam em torno de cem bilhões de dólares por ano, atuando também no setor de hotelaria, informática, aviação, comunicação e finanças, e possuem o maior banco sueco.

A Empresa A é uma planta regional pertencente à Divisão Brasil do grupo do setor de eletrodomésticos. A Divisão Brasil possui uma subdivisão situada na cidade de Curitiba, e duas unidades regionais, uma na cidade de Manaus e outra situada em São Carlos. A estrutura hierárquica da Divisão Brasil é formada pelo presidente da empresa e a diretoria de negócios, com escritório situado no município de São Paulo. $\mathrm{Na}$ unidade de Curitiba, encontram-se os gerentes de divisão, os gerentes e os supervisores das áreas funcionais, e os funcionários operacionais. A Empresa A, por se constituir apenas em uma unidade fabril, possui somente os gerentes e os supervisores das áreas funcionais, e os funcionários operacionais. As principais etapas do processo de fabricação desta empresa se constituem em fabricação e montagem de componentes em linha de montagem. Há dez anos, possuía aproximadamente dois mil funcionários. Atualmente, a empresa conta com um mil, cento e quarenta e seis funcionários. A empresa sofreu redução gradual de funcionários em nível operacional e administrativo.

As principais etapas do processo produtivo desta empresa são, principalmente, montagem e pintura. A maioria dos componentes para a montagem dos produtos é importada e o desenvolvimento de novos produtos ocorre em nível corporativo, cabendo à Divisão Brasil participar apenas de estudos sobre manufaturabilidade e propor pequenas modificações, para adequar o produto ao mercado nacional.

A Empresa B faz parte da Divisão Brasil de corporação norte-americana. A corporação atua no mercado de máquinas e equipamentos para indústria alimentícia, equipamentos para aeroporto e máquinas para a extração de petróleo. A Empresa B faz parte da Divisão Brasil do setor de máquinas e equipamentos para a indústria alimentícia.

A Empresa B possui em sua estrutura hierárquica o gerente mundial, o gerente geral do Cone Sul, os gerentes de departamento (controladoria, recursos humanos, marketing, produção, engenharia e desenvolvimento de produto, quali-

Tabela 1. Caracterização das empresas pesquisadas.

\begin{tabular}{|c|c|c|c|c|c|c|}
\hline \multirow[t]{2}{*}{ Empresa } & \multicolumn{3}{|c|}{ Caracterização da unidade pesquisada } & \multicolumn{3}{|c|}{ Número de empregados } \\
\hline & Matriz & Divisão Brasil & Unidade regional & Empresa & Divisão Brasil & Corporação \\
\hline A & & & $\mathrm{X}$ & 1.146 & 5.000 & 525.000 \\
\hline $\mathrm{B}$ & & $\mathrm{X}$ & & 286 & 321 & 7.000 \\
\hline
\end{tabular}


dade), os supervisores dos departamentos e os funcionários operacionais. A Empresa B é uma unidade de negócio independente e possui duzentos e oitenta e seis funcionários, somando os de nível operacional e administrativo. A empresa não sofreu grande alteração do número de funcionários de dez anos para os dias atuais, apenas ocorreu o enxugamento de um nível hierárquico da empresa: a extinção do gerente de nível médio (Tabela 2).

As principais etapas do processo de fabricação desta empresa se constituem em fundição, usinagem, fabricação de peças e montagem dos equipamentos. A empresa trabalha em processo de produção por lotes ou encomenda, de acordo com as necessidades do mercado e dos clientes.

O principal produto da Empresa B é adquirido por meio de regime de locação pelos clientes, cabendo à empresa fornecer a manutenção e atualização tecnológica de seus produtos da empresa, que são bens de capital. A manutenção do produto, alocado nas instalações industriais dos clientes, exige entrega rápida de peças e pronto serviço de assistência técnica. Por isso, vários funcionários de manutenção trabalham nas instalações dos clientes em contato permanente com a manufatura da empresa.

A empresa está desenvolvendo novas máquinas e equipamentos para aumentar o aproveitamento da capacidade produtiva da empresa, que trabalha com toda capacidade produtiva no primeiro semestre do ano e fica com alto grau de ociosidade no segundo semestre do ano, devido às características peculiares dos clientes que utilizam seus equipamentos.

Os novos produtos da Empresa B são desenvolvidos e testados na cidade da própria divisão e nos potenciais clientes, para a sua aprovação. A empresa está procurando nichos de mercado para aumentar e diversificar a produção, atendendo às exigências de outros mercados consumidores.

Ambas as empresas são líderes no mercado mundial. A Empresa A possui a vice-liderança no mercado nacional e

Tabela 2. Estrutura hierárquica das empresas pesquisadas.

\begin{tabular}{cl}
\hline Empresa & Estrutura hierárquica \\
\hline A & $\begin{array}{l}\text { Gerentes de produção e de recursos humanos, superviso- } \\
\text { res da produção e funcionários operacionais }\end{array}$ \\
& $\begin{array}{l}\text { Gerente mundial, gerente do Cone Sul, gerentes de } \\
\text { departamentos (marketing, recursos humanos, contro- } \\
\text { ladoria, produção, engenharia e desenvolvimento de } \\
\text { produto e qualidade), supervisores de departamentos e } \\
\text { funcionários operacionais }\end{array}$ \\
\hline
\end{tabular}

a Empresa B é também líder no mercado nacional. As duas empresas possuem certificação ISO 9.000 (Tabela 3).

\subsection{O estágio evolutivo das áreas de gestão das empresas pesquisadas}

Pode-se constatar que as duas empresas estudadas se encontram no estágio de integração interna e possuem sua estrutura da estrutura divisional (Tabela 4). A estrutura divisional justifica-se pelo fato das empresas serem formadas por grandes empreendimentos corporativos, que diferenciam seus produtos e se transformam em divisões, formadas de acordo com o produto, com o cliente ou com as diferenças geográficas.

É importante observar que as empresas se encontram no estágio evolutivo de integração interna, pois os gerentes dessas empresas não participam ativamente da formulação das estratégias divisionais. Na Empresa A, a estratégia é definida pela matriz da corporação mundial. A Empresa B possui certa autonomia estratégica pelo fato do gerente geral do Cone Sul estar alocado na empresa.

A Empresa A possui sua forma de departamentalização baseada no produto, cujo principal mecanismo de coordenação é a padronização dos resultados. A unidade fabril de São Carlos faz parte de um grande empreendimento corporativo, ou seja, o trabalho dos funcionários é guiado pelos objetivos e metas da divisão e da corporação.

Já a Empresa B possui estrutura divisional baseada na região geográfica e na proximidade com o cliente. Neste caso, a empresa está mais voltada para a necessidade do mercado e dos clientes. A integração interna desta empresa ocorre por causa do alinhamento das atividades das áreas funcionais com os negócios divisionais. Além disso, existe uma grande integração entre esta unidade de negócio e a corporação.

Foram analisadas nas empresas pesquisadas, as três principais estratégias competitivas, definidas por Schuler e Jackson (1995): custo, qualidade e inovação.

\subsection{Estratégias competitivas adotadas pelas empresas pesquisadas}

As duas empresas apontaram a qualidade como a principal estratégia competitiva da empresa. Ambas relataram que seus produtos possuem qualidade e serviço de atendimento, que as diferenciam das demais, proporcionando para elas vantagem competitiva (Tabela 5).

A Empresa A destacou a qualidade, cuja dimensão mais destacada é a confiabilidade dos bens de consumo duráveis. Como a argumentação preponderante da empresa líder no mercado nacional reside na robustez de seus produtos, a

Tabela 3. Caracterização das empresas pesquisadas.

\begin{tabular}{ccccc}
\hline Empresa & $\begin{array}{c}\text { Posicionamento no } \\
\text { mercado brasileiro }\end{array}$ & $\begin{array}{c}\text { Dimensão da área } \\
\text { fabril }\left(\mathbf{m i l ~ m}^{2}\right)\end{array}$ & Processo de produção & Principais produtos \\
\hline A & $2^{\circ}$ & entre 80 e 100 & massa & bens de consumo duráveis \\
B & $1^{\circ}$ & entre 20 e 40 & lotes & bens de capital \\
\hline
\end{tabular}


Tabela 4. Estágios evolutivos das áreas de gestão e estrutura organizacional.

\begin{tabular}{ccc}
\hline Empresa & $\begin{array}{c}\text { Estágio evolutivo } \\
\text { das áreas de gestão }\end{array}$ & $\begin{array}{c}\text { Estrutura } \\
\text { organizacional }\end{array}$ \\
\hline A & Integração interna & Estrutura divisional \\
B & Integração interna & Estrutura divisional \\
\hline
\end{tabular}

Empresa A, que é líder no mercado mundial, tem como uma de suas estratégias competitivas adquirir a liderança no mercado nacional por meio de melhorias contínuas, objetivando sempre a confiabilidade do produto.

Por causa das atividades da Empresa A, isto é, seus produtos são bens de consumo duráveis voltados para o consumo de massa, a redução de custos não pode ser desprezada para este tipo de negócio. A disputa de mercado por melhores preços é uma constante no ambiente em que esta empresa opera. Por isto, o gerente de produção da Empresa A apontou a qualidade associada a custos competitivos como principal estratégia da organização.

O fator inovação foi considerado importante para a gerência, mas, pelo fato desses produtos serem populares e se encontrarem na fase de maturidade de seu ciclo de vida, não há inovação substancial em características dos produtos, apenas em cores e design.

A Empresa B também destacou a qualidade de seus equipamentos como principal estratégia competitiva da empresa. A empresa apontou a qualidade relacionada à diferenciação de seus produtos, isto é, a empresa apresenta produtos com qualidade superior e diferenciada da concorrência. A concorrência não possui o mesmo desempenho em qualidade $\mathrm{e}$ atendimento. Desta forma, a principal preocupação das engenharias de produto e de fabricação reside no aperfeiçoamento de produtos existentes e no lançamento de novos modelos.

A inovação também é preocupação estratégica da alta gerência. A Divisão Brasil em Araraquara tem seu próprio setor de desenvolvimento de produto, e o alto nível de sofisticação, dos produtos e processos de fabricação, desta unidade de negócio é, em alguns casos, superior ao de unidades norte-americanas.

Pelo fato dos produtos e serviços da empresa serem muito diferenciados dos concorrentes nacionais, o custo não é preocupação principal da gerência. Cuidados na redução de custos são tomados, para evitar que os clientes importem produtos similares de fortes concorrentes no mercado global.

\subsection{0 grau de participação dos funcionários na formulação da estratégia empresarial}

A formulação da estratégia empresarial ocorre de maneira diferenciada nas duas empresas pesquisadas (Tabela 6). $\mathrm{Na}$ Empresa A, a estratégia é corporativa, isto é, ela é definida globalmente para todas as empresas do grupo. A estratégia nacional é adaptada pelo presidente da Divisão Brasil, situada no município de São Paulo, juntamente com os membros da diretoria. A gerência da Empresa $\mathrm{A}$ não participa direta-
Tabela 5. Estratégias competitivas.

\begin{tabular}{ccc}
\hline Empresa & $\begin{array}{c}\text { Principal } \\
\text { estratégia }\end{array}$ & $\begin{array}{c}\text { Preocupação } \\
\text { estratégica associada }\end{array}$ \\
\hline A & Qualidade & Custo \\
B & Qualidade & Inovação \\
\hline
\end{tabular}

mente da formulação da estratégia nacional, cabendo a ela somente a comunicação das diretrizes estratégicas. A comunicação destas diretrizes ocorre em cascata, de cima para baixo, através dos níveis hierárquicos da organização. Segundo a gerência da unidade, as diretrizes são adaptadas para cada planta fabril, indo ao encontro do planejamento estratégico.

A Empresa B possui maior autonomia para definir sua estratégia nacional pelo fato de ter presentes, na empresa, o gerente mundial da divisão e o gerente geral do Cone Sul. A presença da cúpula estratégia da organização aumenta a autonomia da empresa e garante que a estratégia esteja focada diretamente no mercado consumidor. Neste caso, a formulação da estratégia nacional é realizada na empresa pelo gerente mundial e o gerente do Cone Sul, com a presença de outros gerentes de área, alinhada à estratégia corporativa. A comunicação da estratégia ocorre de forma clara em efeito cascata, para toda a organização. Segundo o gerente geral da organização, todos têm conhecimento da estratégia empresarial, principalmente os funcionários que estão em contato direto com os clientes.

Ambas as empresas reconheceram que a estratégia empresarial é confidencial e de competência exclusiva dos gerentes de cúpula. Os demais funcionários podem participar indiretamente da estratégia empresarial, por meio de reuniões com gerentes de departamento, para delinear a estratégia departamental, que deve estar alinhada com a estratégia organizacional.

\subsection{Programas de Qualidade nas empresas pesquisadas}

Ambas as empresas pesquisadas possuem certificados ISO 9000. As duas empresas possuem, como principal estratégia competitiva, a qualidade de seus produtos e serviços, obtendo a certificação como consequiência da participação e o envolvimento de todos os membros da organização. A qualidade é pensada na forma de mudança de atitude das pessoas e conscientização para a qualidade como um todo (Tabela 7).

A Empresa A possui certificação ISO 9001 que abrange produtos, pessoas e processos, e, recentemente, adquiriu a ISO 14001, que trata sobre gestão ambiental. Pode-se afirmar que a Empresa A encontra-se na etapa "garantia da qualidade" dos movimentos pela qualidade, segundo Garvin (1992). A empresa possui programas e sistemas que coordenam as atividades de todos os departamentos e no seu processo produtivo, para prevenir falhas da qualidade. A alta gerência apresenta um envolvimento periférico com o projeto, participando apenas no planejamento da qualidade. A unidade não dispõe de um gerente de qualidade, apenas três 
Tabela 6. Responsáveis pela formulação da estratégia da Divisão Brasil.

\begin{tabular}{cl}
\hline Empresa & Responsáveis pela formulação da estratégia nacional \\
\hline A & $\begin{array}{l}\text { Presidente e diretoria da divisão juntamente com a cúpula } \\
\text { estratégica da corporação (não há participação dos geren- } \\
\text { tes da Empresa A na formulação da estratégia da divisão) }\end{array}$ \\
B & $\begin{array}{l}\text { Gerente mundial da divisão, gerente geral do Cone Sul } \\
\text { e alguns gerentes das áreas funcionais da Empresa B }\end{array}$ \\
\hline
\end{tabular}

supervisores que têm por função viabilizar os programas de qualidade definidos em nível corporativo.

A Empresa B também possui certificação ISO 9001 e, no ano de 2003, tem por objetivo concorrer ao Prêmio da Fundação Nacional da Qualidade, excelência em qualidade no país. Segundo o gerente de qualidade da Empresa B, a empresa está reunindo esforços de todas as pessoas da organização para atingir este objetivo. Esta empresa encontra-se na etapa "gerenciamento estratégico da qualidade", segundo Garvin (1992). A Empresa B enfatiza o planejamento estratégico e o estabelecimento de objetivos para toda a organização, a fim de atender às necessidades dos clientes e do mercado. A alta gerência está envolvida juntamente com toda a organização, para a obtenção da qualidade, como forma de satisfação do consumidor e diferenciação da concorrência.

\subsection{Gestão de recursos humanos nas empresas pesquisadas}

De acordo com os gerentes de recursos humanos das empresas pesquisadas, o departamento de recursos humanos foi o que mais sofreu modificações nos últimos dez anos, sofrendo mudanças físicas, estruturais e conceituais. A principal mudança foi a terceirização de atividades inerentes ao departamento, como folha de pagamento, recrutamento e seleção, além do enxugamento do pessoal. A Empresa A possui uma pessoa apenas responsável pelo departamento e a Empresa B possui três pessoas no departamento. Além desta mudança principal, a gerência de recursos humanos passa a desempenhar funções mais estratégicas na organização, tais como desenvolvimento organizacional, gestão das competências e gestão do clima organizacional.

Os gerentes das duas empresas identificam duas prioridades básicas na gestão de recursos humanos: instrumentalizar e capacitar pessoas para o crescimento organizacional. Ambos afirmam que o diferencial entre uma organização e outra é o capital intelectual que esta possui.

Para reforçar esta postura da gerência, analisam-se atividades como treinamento, avaliação de desempenho e os sistemas de recompensa ao trabalhador.

A Empresa A possui programas de treinamento para o nível operacional na Escola de Manufatura. Este treinamento é disponibilizado a todos os funcionários da empresa e realizado todos os dias. Um grupo de oito funcionários é treinado na Escola da Manufatura, onde se encontra uma réplica da
Tabela 7. Programas de qualidade.

\begin{tabular}{lll}
\hline Empresa & Certificação de qualidade & $\begin{array}{l}\text { Estágio do movimento } \\
\text { da qualidade }\end{array}$ \\
\hline A & ISO 9001 e ISO 14001 & $\begin{array}{l}\text { Garantia da qualidade } \\
\text { Gerenciamento estraté- } \\
\text { gico da qualidade }\end{array}$ \\
\hline
\end{tabular}

linha de montagem simulando parte do processo produtivo. Os funcionários são treinados em funções específicas com visão global do processo, tornando-se trabalhadores multifuncionais. Para as outras áreas da empresa, o departamento de recursos humanos desenvolve treinamento de acordo com necessidades específicas da organização.

Esta empresa não possui sistema de medição de desempenho. A corporação está desenvolvendo estudos sobre um sistema de medição de desempenho formal em nível corporativo. A empresa possui uma avaliação do desempenho global, que está vinculado ao programa de participação nos resultados. Os sistemas de recompensa estão amarrados a uma escala salarial que tem como base pesquisas de mercado.

A Empresa B não possui programas de treinamento gerais para a organização. O treinamento dos funcionários está vinculado ao sistema de medição de desempenho, denominado sistema de medição de desenvolvimento do funcionário. O sistema de medição de desenvolvimento avalia as competências dos funcionários necessárias para o negócio da empresa, cujo objetivo é definir ações de desenvolvimento. O funcionário é avaliado juntamente com o seu supervisor, sendo consideradas as habilidades e deficiências do funcionário no seu trabalho, a fim de serem propostos treinamentos para o desenvolvimento dos funcionários nas competências debilitadas.

Segundo o gerente de recursos humanos da Empresa B, e não possui um sistema formalizado de recompensa. A principal recompensa para ele é a confiança mútua entre a empresa e o funcionário. Formalizados, a empresa possui somente o reconhecimento por tempo de serviço e a participação dos funcionários nos resultados, o qual é denominado "mérito pela performance" (Tabela 8).

Analisando as políticas de recursos humanos nas duas empresas, pode-se afirmar que, na Empresa A, a gestão de recursos humanos está orientada por negócios divisionais, realizando programas voltados para a produtividade e os objetivos organizacionais. A participação das atividades de recursos humanos restringe-se à sua integração interna no âmbito divisional, não participando efetivamente do planejamento estratégico. Por estas características principais, a empresa encontra-se no estágio de integração funcional de recursos humanos, como conceituado por Meshoulam e Baird (1987).

A Empresa B apresenta a gestão de recursos humanos mais integrada com a gestão de negócios da empresa. A empresa tem programas voltados para o diagnóstico da cultura organizacional e do ambiente externo, a fim de desenvolver sistemas de medição de desempenho, voltados para a efici- 
Tabela 8. Políticas de recursos humanos.

\begin{tabular}{clll}
\hline Empresa & Treinamento e desenvolvimento & Sistemas de medição de desempenho & Sistemas de recompensa \\
\hline A & $\begin{array}{l}\text { Treinamento voltado para a } \\
\text { especialização técnica }\end{array}$ & Inexistente & Participação nos resultados \\
B & $\begin{array}{l}\text { Treinamento atrelado às competên- } \\
\text { cias do trabalhador }\end{array}$ & $\begin{array}{l}\text { Sistema de medição de } \\
\text { desenvolvimento do trabalhador }\end{array}$ & $\begin{array}{l}\text { Reconhecimento por tempo de serviço } \\
\text { e participação nos resultados }\end{array}$ \\
\hline
\end{tabular}

Tabela 9. Redução do número de funcionários das empresas pesquisadas.

\begin{tabular}{ccc}
\hline Empresa & \multicolumn{2}{c}{ Redução número de funcionários } \\
\hline & $\mathrm{n}^{\text {o }}$ de funcionários & $\mathrm{n}^{\text {o }}$ de funcionários \\
em 1990 & em 2002 \\
$\mathrm{~A}$ & 2000 & 1146 \\
$\mathrm{~B}$ & 500 & 321 \\
\hline
\end{tabular}

ência e eficácia dos funcionários, diretamente relacionadas às necessidades do negócio. A gestão de recursos humanos está orientada pela companhia e integrada com a direção estratégica dos negócios da empresa, o que permite caracterizar seu estágio como integração estratégica, de acordo com definição Meshoulam e Baird (1987).

\subsection{Desenvolvimento do empowerment nas empresas pesquisadas}

As empresas estudadas sofreram profundas mudanças organizacionais nos últimos dez anos, para continuarem competindo no mercado em que atuam. Os gerentes das duas empresas apresentaram como principais mudanças:

- a criação de unidades de negócios;

- a redução de níveis hierárquicos (downsizing);

- a redução do número de funcionários (Tabela 9); e

- a maior participação das áreas funcionais na gestão do negócio.

A Empresa A se constituiu em uma unidade de negócio focalizado na manufatura de seus produtos com reduzida área administrativa, isto é, uma unidade fabril, cujos esforços estão voltados exclusivamente para a produção.

A Empresa B transformou-se numa área de negócio com elevado grau de autonomia diante da corporação, que transferiu a gerência mundial desta área do negócio dos Estados Unidos para a Divisão Brasil, a fim de garantir a maior aproximação entre a alta gerência e os clientes dos seus produtos.

Como mudança organizacional importante ocorrida nas duas empresas, teve-se a transformação das áreas de recursos humanos e qualidade em áreas de suporte aos negócios. Com a terceirização das funções tradicionais da gestão de recursos humanos, esta área passa a se dedicar a programas e políticas mais estratégicas relacionadas com os objetivos das empresas. A área de qualidade muda sua posição de inspeção e controle para gerenciar a confiabilidade do produto pelo comprometimento e satisfação dos clientes internos e externos da organização.

As duas empresas sofreram também, nos últimos dez anos, redução de níveis hierárquicos e redução do número de funcionários. $\mathrm{O}$ crescente avanço tecnológico e da tecnologia de informação, a necessidade de respostas rápidas, pelas mudanças no ambiente competitivo, e a necessidade de redução de custos para continuarem competindo, levaram as empresas ao enxugamento de pessoal e ao donwsizing.

Há dez anos, a Empresa A apresentava um quadro de pessoal com dois mil funcionários e o departamento de recursos humanos com oitenta e seis funcionários. Hoje, apresenta um quadro com mil cento e quarenta e seis funcionários totais e quatro funcionários na área de recursos humanos: a gerente, dois médicos e um enfermeiro de segurança. A empresa também sofreu redução gradual dos seus níveis hierárquicos, apresentando na unidade apenas o nível gerencial, de supervisão de área, supervisor de produção e operacional.

A Empresa B também teve seu quadro de pessoal reduzido de quinhentos funcionários, dez anos atrás, para trezentos e vinte e um na Divisão Brasil, com reduções, principalmente, nas áreas administrativas. $\mathrm{O}$ departamento de recursos humanos, por exemplo, teve seu quadro diminuído de quarenta para três funcionários: um gerente, um analista e uma secretária.

Para a obtenção de melhores resultados na unidade de negócios, a empresa reduziu três níveis hierárquicos em dez anos. Os níveis eliminados eram ocupados por gerentes de nível médio com função de supervisão.

No entanto, a redução dos funcionários não implicou distanciamento das áreas funcionais da gestão estratégica de negócio. Pelo contrário, segundo depoimentos dos gerentes, as áreas funcionais se aproximaram mais das decisões estratégicas das empresas, principalmente na Empresa B. Alguns gerentes da Empresa B participam, juntamente com o gerente de divisão, da definição e consecução dos objetivos estratégicos da organização.

As principais mudanças organizacionais ocorridas levaram as empresas a um aumento gradual e espontâneo do empowerment. A formação de unidades de negócio, a redução do número de funcionários e o donwsizing aproximam lentamente as áreas funcionais e os funcionários do processo decisório das empresas.

Observa-se que a Empresa A encontra maior dificuldade para o processo de empowerment por causa da natureza do negócio e do processo produtivo. A empresa fabrica bens de consumo duráveis no processo de produção em massa, não produzindo nem desenvolvendo peças. Trabalha apenas com linha de montagem. Apesar da empresa alegar que os 
funcionários são treinados para funções específicas e que conheceram todo o processo produtivo, ainda estão amarrados à linha de produção, os incapacitando para a tomada de decisão. Os funcionários tornam-se polivalentes dentro da manufatura, mas não suas atividades, que não se estenderam a outras áreas da empresa.

A Empresa B encontra mais facilidade para o processo de empowerment pela natureza do negócio, do processo produtivo e da proximidade do cliente. Neste caso, a empresa desenvolve produtos para clientes específicos em unidades de negócio e equipes multidisciplinares. No chão de fábrica, a produção ocorre por lotes, não há linha de montagem. Os funcionários são treinados em cada parte do processo produtivo, e a montagem do equipamento ocorre de acordo com as necessidades dos clientes.

As empresas pesquisadas reconheceram o empowerment dos funcionários como um fator importante para aumentar a rapidez na tomada de decisões e solução de problemas. Elas associam o empowerment ao conhecimento, pois somente trabalhadores bem treinados tecnicamente e conscientes do ambiente interno e externo da organização desenvolvem o empowerment. Para a maioria dos gerentes entrevistados o grande desafio para o desenvolvimento do empowerment está na resistência dos gerentes e dos trabalhadores. Os gerentes, porque temem compartilhar as informações, e os trabalhadores, porque não se sentem preparados para assumir novas responsabilidades e terem autonomia para a tomada de decisões. As pessoas resistem ao empowerment porque se sentem ameaçadas com as mudanças.

\subsection{Tipos de empowerment nas empresas pesquisadas}

É muito difícil enquadrar as empresas na tipologia do empowerment apresentada por Ford e Fottler (1996). As empresas não são caracterizadas por um único tipo específico de empowerment, como foi descrito na parte teórica deste trabalho. A autoridade e a responsabilidade para a tomada de decisão são variáveis dentro da mesma organização.

Após a análise nas empresas estudadas, pode-se dizer que o empowerment está mais próximo dos funcionários que estabelecem um contato maior com o cliente.

A Empresa A é uma multinacional sueca, cuja maioria das práticas e estratégias são realizadas pela matriz. Os gerentes da unidade brasileira alinham suas estratégias departamentais com a estratégia empresarial e as repassam para os funcionários. Os gerentes desta unidade possuem autoridade para intervirem no conteúdo de seu trabalho e pouca para intervirem na estratégia empresarial, no que diz respeito ao ambiente externo da organização. Os funcionários de chão de fábrica estão presos à linha de montagem, conseguindo pouca intervenção no conteúdo de seu trabalho, apesar de serem treinados para possuírem uma visão global do processo.

A Empresa B, está situada proximamente do mercado consumidor e os gerentes de divisão possuem maior autonomia na definição da estratégia empresarial brasileira, juntamente com a matriz norte-americana. A gestão de recursos humanos está mais voltada para as necessidades do negócio, e os funcionários produzem de acordo com as necessidades e especificações do cliente. Segundo o gerente geral desta empresa, o funcionário operacional, que trabalha diretamente com o cliente, possui maior responsabilidade e autonomia do que pessoas que exercem funções administrativas internas dentro da empresa.

Os funcionários da Empresa B, tanto os gerentes como os operários, possuem um empowerment maior para realizarem seus trabalhos. Quanto à Empresa $\mathrm{A}$, o empowerment já é mais difícil de ser obtido, pela não participação direta dos gerentes funcionais na formulação da estratégia divisional, e ao processo produtivo em massa.

É importante ressaltar que, apesar de terem sido entrevistados os gerentes das áreas funcionais das Empresas A e B, deve-se considerar que os gerentes da Empresa A estão hierarquicamente mais distantes da cúpula estratégica da corporação do que os gerentes da Empresa B. Este distanciamento hierárquico e físico dificulta uma maior participação na formulação da estratégia empresarial.

Analisando as políticas de recursos humanos nas duas empresas, pode-se afirmar que na Empresa A, a gestão de recursos humanos está orientada por negócios divisionais, realizando programas voltados para a produtividade e os objetivos organizacionais. A participação das atividades de recursos humanos restringe-se à sua integração interna no âmbito divisional, não participando efetivamente do planejamento estratégico. Por estas características principais, a empresa encontra-se no estágio de integração funcional de recursos humanos, como conceituado por Meshoulam e Baird (1987).

\section{Conclusões}

Conclui-se este trabalho, analisando os fatores que contribuíram para o empowerment nas empresas pesquisadas, suas particularidades e as limitações que as empresas encontram para o seu desenvolvimento.

O empowerment não ocorreu como um programa planejado pelo fato de não ter sido observado nenhum programa formal intitulado empowerment ou algo semelhante. $\mathrm{O}$ aumento do empowerment dos gerentes e funcionários é uma consequiência do processo evolutivo das organizações e do ambiente em que estas organizações estão inseridas. As organizações sofreram alterações internas para sobreviverem às grandes mudanças do ambiente externo.

Fatores externos como a globalização da economia, crescente avanço tecnológico, aumento da competitividade e crescente exigência do mercado consumidor levaram as organizações a reduzirem custos e aumentarem a velocidade de resposta para atender às novas demandas. Como principais mudanças internas, têm-se a redução dos funcionários, a diminuição dos níveis hierárquicos e a descentralização da autoridade. Isto acarretou uma aproximação gradual dos 
funcionários com o processo decisório das empresas.

O empowerment não foi implementado nas empresas estudadas de forma homogênea, isto é, uma empresa inteira não possui um único tipo de empowerment, conforme afirmam Ford e Fottler (1996), isto é, ou todos os funcionários da empresa trabalham com nenhum empowerment ou todos são autogerenciáveis. Fatores como natureza do negócio, mix de produtos e serviços, processo produtivo, estrutura hierárquica, estratégia competitiva e outros, influenciam na necessidade das organizações em adotarem um maior ou menor empowerment a determinados funcionários.

$\mathrm{O}$ estudo de casos, realizado em duas empresas com processos produtivos e linha de produtos diferentes, apresenta níveis de empowerment bastante diferenciados.

A Empresa A fabrica bens de consumo duráveis em linha de produção, tendo como principal estratégia competitiva a qualidade a baixos custos de produção. Nesta organização, os funcionários de chão de fábrica não participam e não têm necessidade de participar do processo decisório da empresa. A estes funcionários cabe um treinamento técnico necessário para operar as máquinas e manter um bom funcionamento na linha de produção, assegurando a qualidade e a produtividade. Os gerentes de recursos humanos e produção possuem apenas autoridade e autonomia no que diz respeito ao conteúdo de seus trabalhos, para atingir os objetivos e metas da corporação. A estes gerentes não cabe decidir sobre as estratégias empresariais voltadas para o ambiente externo e mercado consumidor.

A Empresa B fabrica máquinas e equipamentos em processo produtivo por lotes, tendo como principal estratégia competitiva a qualidade tendendo à inovação. Neste caso, as características da empresa favorecem o empowerment do gerente geral e de alguns gerentes das áreas funcionais da organização, que têm poder de decisão junto ao gerente mundial da organização para a definição da estratégia empresarial; dos engenheiros de produto que necessitam de maior liberdade e autonomia, para desenvolverem novos produtos; e dos técnicos de manutenção, que representam a empresa no cliente, e têm maior autoridade e responsabilidade para a resolução dos problemas.
A Empresa B, ao contrário da Empresa A, necessita de mais funcionários com empowerment, pela estratégia da empresa tender para a inovação e pela proximidade do negócio da empresa com o cliente.

Outro fator bastante importante que favorece ao empowerment foi a proximidade dos funcionários com a necessidade do cliente. A empresa que fabrica em massa não possui uma clientela específica e os funcionários não têm contato direto com os consumidores de seus produtos. Já a empresa, que fabrica de acordo com as especificações e necessidades do cliente, e que monta equipamentos ou vende produtos diretamente dentro da empresa do cliente, sente necessidade de funcionários com maior competência e autonomia para atendê-los.

Pode-se afirmar que as dimensões do empowerment em que as empresas encontram maiores limitações são: participação na formulação da estratégia, avaliação de desempenho e reconhecimento do trabalho dos gerentes e funcionários.

A participação na formulação da estratégia cabe somente aos gerentes de cúpula estratégica, pelo fato das principais estratégias competitivas das empresas serem confidenciais. Os gerentes das áreas funcionais participam somente da estratégia de seus departamentos e alguns deles participam da formulação das estratégias de negócios, não participando da formulação da estratégia corporativa.

O sistema de avaliação de desempenho, principalmente da Empresa A, não é adequado ao empowerment, porque a medição é realizada por meio de indicadores financeiros de resultados. Já, os sistemas de recompensa das duas empresas não reconhecem o trabalhador para o empowerment, as empresas apenas rateiam os lucros e resultados financeiros gerais por níveis salariais e não por participação, competência e trabalhos realizados.

Outro fator encontrado nas empresas, não analisado na teoria, que dificulta o desenvolvimento do empowerment, foi a resistência das pessoas às mudanças. Do ponto de vista da gerência das duas empresas estudadas, não são todas as pessoas que estão preparadas para trabalhar com empowerment. Para eles, as pessoas temem por mudanças e aumento de responsabilidades nos seus ambientes de trabalho.

\section{Referências Bibliográficas}

CUNNINGHAM, I.; HYMAN, J. The poverty of empowerment? A critical case study. Personal Review, v. 28, n. 3, p. 192-207, 1999.

FORD, R. C.; FOTTLER, M. D. Empowerment: a matter of degree. IEEE Engineering Management Review, v. 24, n. 3 , p. 19-24, Fall, 1996.

GARVIN, D.A. Gerenciando a qualidade: a visão estratégica e competitiva. Rio de Janeiro, Qualitymark, 1992.

HERRENKOHL, R. C.; JUDSON, G. T.; HEFFNER, J. A. Defining and measuring employee empowerment. Journal of
Applied Behavioral Science, v. 35, n. 3, p. 373-389, Sep. 1999.

MESHOULAM, I.; BAIRD, L. Proactive human resource management. Human Resource Management, v. 26, n. 4, p. 83-502, Winter, 1987.

MINTZBERG, H. Criando organizações eficazes: estruturas em cinco configurações. São Paulo, Atlas, 1995.

PFEIFFER, I.; DUNLOP, J. Increasing productivity through empowerment. Supervisory Management, p. 8-17, Jan., 
1990.

RODRIGUES, C.H.R. Empowerment e estágios evolutivos das áreas de gestão: estudo de casos em empresas manufatureiras. Dissertação (Mestrado em Engenharia de Produção) - Escola de Engenharia de São Carlos, Universidade de São Paulo, São Carlos, 2002.

RODRIGUES, C.H.R.; SANTOS, F.C.A. Empowerment: ciclo de implementação, dimensões e tipologia. Gestão \& Produção, v. 8, n. 3, p. 237-249, dez., 2001.

SANTOS, F.C.A. Similaridades dos estágios evolutivos das áreas de gestão. Revista de Administração (USP), v. 36, n. 4, p. 18 - 32, out.-dez, 2001.
SANTOS, F.C.A. Dimensões competitivas e estratégia de recursos humanos; importância para a gestão de negócios em empresas manufatureiras. Tese (Doutorado em Administração de Empresas) - Escola de Administração de Empresas de São Paulo, Fundação Getúlio Vargas, São Paulo, 1998.

SCHULER, R. S.; JACKSON, S. E. Linking competitive strategies with human resource management practices. IN: MINER, J.B.; CRANE, D.P. Advances in the practice, theory and research of strategic of human resource management. New York, Harper Collins College, 1995.

WILKINSON, A. Empowerment: theory and practice. Personnel Review. v. 27, n. 1, p. 40-56, 1998.

\title{
EMPOWERMENT: A CASE STUDY IN MANUFACTURING COMPANIES.
}

\begin{abstract}
An analysis is made here of the empowerment implementation process in two manufacturing companies. Empowerment is a work design approach aimed at delegating decision making, autonomy and employee participation in company management. The development of empowerment is analyzed through the evolutionary stages of management areas, organizational configurations, competitive strategies, and human resources and quality management. A case study of two manufacturing companies in the state of São Paulo was conducted to analyze the degree of employee participation according to the stages of evolution of their management areas. The conclusions section of this article discusses the favorable factors, peculiarities and limitations of empowerment revealed during these case studies.
\end{abstract}

Keywords: empowerment, evolution stages of management areas, human resource management, quality management, company strategy. 